48 Rey JM, Walter G, Giuffrida M. Australian psychiatrists today: proud of their profession but stressed and apprehensive about the future. Aust $N$ Z J Psychiatry 2004; 38(3): 105-10.

49 Rotstein S, Jenkins K. Career satisfaction and work stressors in psychiatrists and psychiatry trainees in Australia and New Zealand. Australas Psychiatry 2017; 25(2): 172-4.

50 Ruskin R, Sakinofsky I, Bagby R, Dickens S, Sousa G. Impact of patient suicide on psychiatrists and psychiatric trainees. Acad Psychiatry 2004; 28(2): 104-10

51 Sprang G, Clark JJ, Whitt-Woosley A. Compassion fatigue, compassion satisfaction, and burnout: factors impacting a professional's quality of life. J Loss Trauma 2007; 12(3): 259-80.

52 Strasburger LH, Miller PM, Commons ML, Gutheil TG, LaLlave J. Stress and the forensic psychiatrist: a pilot study. J Am Acad Psychiatry Law 2003: 31(1): 18-26.
53 Vicentic S Gasic MJ Milovanovic A Tosevski DL Nenadovic A Damjanovic $A$, et al. Burnout, quality of life and emotional profile in general practitioners and psychiatrists. Work 2013; 45(1): 129-38.

54 Volpe U, Luciano M, Palumbo C, Sampogna G, Del Vecchio V, Fiorillo A. Risk of burnout among early career mental health professionals. $J$ Psychiatr Ment Health Nurs 2014; 21(9): 774-81.

55 Walter G, Rey JM, Giuffrida M. What is it currently like being a trainee psychiatrist in Australia? Australas Psychiatry 2003; 11(4): 429-34.

56 Yanchus NJ, Periard D, Osatuke K. Further examination of predictors of turnover intention among mental health professionals. J Psychiatr Ment Health Nurs 2017; 24(1): 41-56.

57 Seligman M. PERMA and the building blocks of well-being. J Posit Psychol 2018; 13(4): 333.

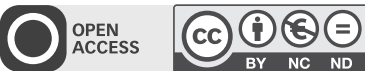

\title{
The London memory service audit and quality improvement programme
}

\author{
Laura D. Cook, ${ }^{1}$ Katie E. Nichol, ${ }^{1}$ Jeremy D. Isaacs ${ }^{1,2}$
}

BJPsych Bulletin (2019) 43, 215-220, doi:10.1192/bjb.2019.18

'Dementia Clinical Network NHS England (London Region); ${ }^{2}$ St George's University Hospitals NHS Foundation Trust

Correspondence to Laura D. Cook (laura.cook18@nhs.net)

First received 5 Nov 2018, final revision 21 Jan 2019, accepted 10 Feb 2019

(c) The Authors 2019. This is an Open Access article, distributed under the terms of the Creative Commons Attribution-NonCommercial-

NoDerivatives licence (http:// creativecommons.org/licenses/by-ncnd/4.0/), which permits non-

commercial re-use, distribution, and reproduction in any medium, provided the original work is unaltered and is properly cited. The written permission of Cambridge University Press must be obtained for commercial re-use or in order to create a derivative work.

\begin{abstract}
Aims and method Memory services have expanded significantly in the UK, but limited performance data have been published. The aim of this programme was to determine variation in London memory services and address this through service improvement projects. In 2016 London memory services were invited to participate in an audit consisting of case note reviews of at least 50 consecutively seen patients.
\end{abstract}

Results Ten services participated in the audit, totalling 590 patients. Variation was noted in neuroimaging practice, neuropsychology referrals, diagnosis subtype, non-dementia diagnoses, waiting times and post-diagnostic support. Findings from the audit were used to initiate four service improvement projects.

Clinical Implications Memory services should consider streamlining pathways to reduce waiting times, implementing pathways for patients who do not have dementia, monitoring appropriateness of neuroimaging, and working with commissioners and primary care to ensure that access to post-diagnostic interventions is consistent with the updated National Institute for Health and Care Excellence (NICE) dementia guideline.

Declaration of interest J.D.I. received an honorarium from Biogen for an advisory board. He has been Principal Investigator in clinical trials sponsored by Roche, Merck and Lupin pharmaceuticals. He was a member of the 2018 NICE dementia clinical guideline committee.

Keywords Dementia; memory assessment service; audit; service improvement.
The Prime Minister's challenge on dementia $2020^{1}$ emphasises timely diagnosis, high quality care and research participation. Furthermore, the government has set the first ever national ambition on dementia diagnosis; that two-thirds of the estimated number of people with dementia should receive a diagnosis. The government's 2018/2019 mandate to NHS England also sets an expectation to improve the quality of care and support for people with dementia. ${ }^{2}$ For these commitments to be realised, greater numbers of patients will need to be assessed in memory services, placing additional demands on a sector that has already undergone rapid expansion since the National Dementia Strategy was published in 2008.

Although dementia diagnosis rates for clinical commissioning groups (CCGs) in England are published monthly by NHS Digital, limited data on memory service performance are available. The London Dementia Clinical Network has a remit to reduce variation in care in London memory services 
through targeted service improvement projects. In 2015, the Network completed a pilot audit of eight London memory services. Our findings suggested significant differences in waiting times, diagnostic practices, access to post-diagnostic treatment and support, and research participation; ${ }^{3}$ however, firm conclusions could not be drawn owing to the relatively small sample size (22-50 patients per service). After refining the audit methodology, a further audit aiming for a larger sample size was performed in early 2016 . We report here the findings of the audit and the ensuing quality improvement programme developed by the London Dementia Clinical Network.

\section{Method}

Using the 2015 pilot audit as a template, a best practice clinical data-set was developed by an expert reference group consisting of primary and secondary care clinicians, memory service managers and commissioners. The group reviewed existing standards, e.g. Memory Services National Accreditation Programme (MSNAP) standards and National Institute for Health and Care Excellence (NICE) guidance. The data-set consisted of a brief organisational checklist followed by data extracted from patient case notes covering the following areas: patient demographics, referral, assessment, investigation, diagnosis, treatment, follow-up and research participation.

Clinical and service leads for the 30 London memory services were invited to participate in the audit. Services were given 11 weeks to complete the audit. The sampling frame stipulated auditing consecutively referred patients from 1 January 2016 until a minimum of 50 patients had been seen. Services were informed that they would be provided with their individual results; however, when comparative data were presented, services would be anonymised.

Data were collected locally by the memory services using the audit tool spreadsheet. Completed data-sets were sent electronically to the London Dementia Clinical Network for analysis. No statistical tests were performed.

Four specific service improvement projects were initiated following analysis of the audit results: (1) streamlining memory services pathways, (2) implementing NICE guidelines, (3) non-dementia pathways and (4) neuroimaging guidance.

\section{Results}

Ten of the 30 London memory services took part in the audit. There was representation from inner and outer, and north and south London, and from each sustainability and transformation partnership footprint except North West London.

A total of 590 referrals were received, of which 502 patients were seen, ranging from 39 to 68 per service.

\section{Patient demographics}

Overall, $33 \%$ of referrals were of non-White British ethnicity, varying from $10 \%$ to $54 \%$ per service; this is comparable to contemporaneous population projection data, which estimated that, in 2016, 37\% of Londoners over the age of 65 were of a non-White British ethnicity. ${ }^{4}$
The median age at referral ranged from 79 to 82 years, and the percentage of female referrals ranged from $51 \%$ to $68 \%$.

Of the 388 patients asked, $10 \%$ were current smokers, which is in line with national reporting. ${ }^{5}$

Reported alcohol consumption was lower than expected; ${ }^{6}$ overall, $34 \%$ of patients reported that they consumed alcohol. However, in one service only $4 \%$ of patients reported that they consumed alcohol.

\section{Memory service assessment}

Fifty-six referrals were rejected; the most common reasons were that the patient was already under another care provider (13), they already had a known dementia diagnosis (10) or the referral was passed directly to tertiary care (9). Overall, 16 patients declined assessment (3\%).

About half of all patients were assessed in clinic, but there was considerable variation between services with the proportion of patients seen in clinic (as opposed to in their own home) varying between $9 \%$ and $95 \%$.

\section{Neuroimaging}

Variation was noted in neuroimaging practice. The percentage of patients deemed not to require a scan for dementia diagnosis varied from $6 \%$ to $46 \%$ (Fig. 1). Fourteen per cent of patients had previously had a scan and were deemed not to require repeat imaging. Of those patients who did have a scan, the percentage who had computed tomography (CT) (rather than magnetic resonance imaging (MRI)) varied from $2 \%$ to $58 \%$.

\section{Neuropsychology}

Overall, $11 \%$ of patients (53) were referred to neuropsychology; in seven cases, no neuropsychology service was available, and two patients declined. The percentage of patients who were seen by neuropsychology varied between services from $4 \%$ to $19 \%$.

\section{Diagnosis}

Overall, $85 \%$ of patients aged $<65$ years at referral were deemed not to have dementia after assessment. In patients aged 65 and over, $61 \%$ were given a diagnosis of dementia and $21 \%$ a diagnosis of mild cognitive impairment (MCI).

In patients who were not diagnosed with dementia (175), the most common other diagnoses were MCI (94), primary psychiatric diagnosis (20) and subjective cognitive impairment (9). It was reported that 27 patients had 'no illness'.

Dementia subtype diagnoses varied significantly between services (Fig. 2; Table 1) and varied from consensus estimates. ${ }^{7}$

\section{Waiting times}

The average waiting time between the referral being received and the patient being seen for an initial assessment varied from 2 to 13 weeks. Overall, $26 \%$ of patients were assessed within 2 weeks and $52 \%$ within 4 weeks. The audit tool 
Fig. 1 Imaging.

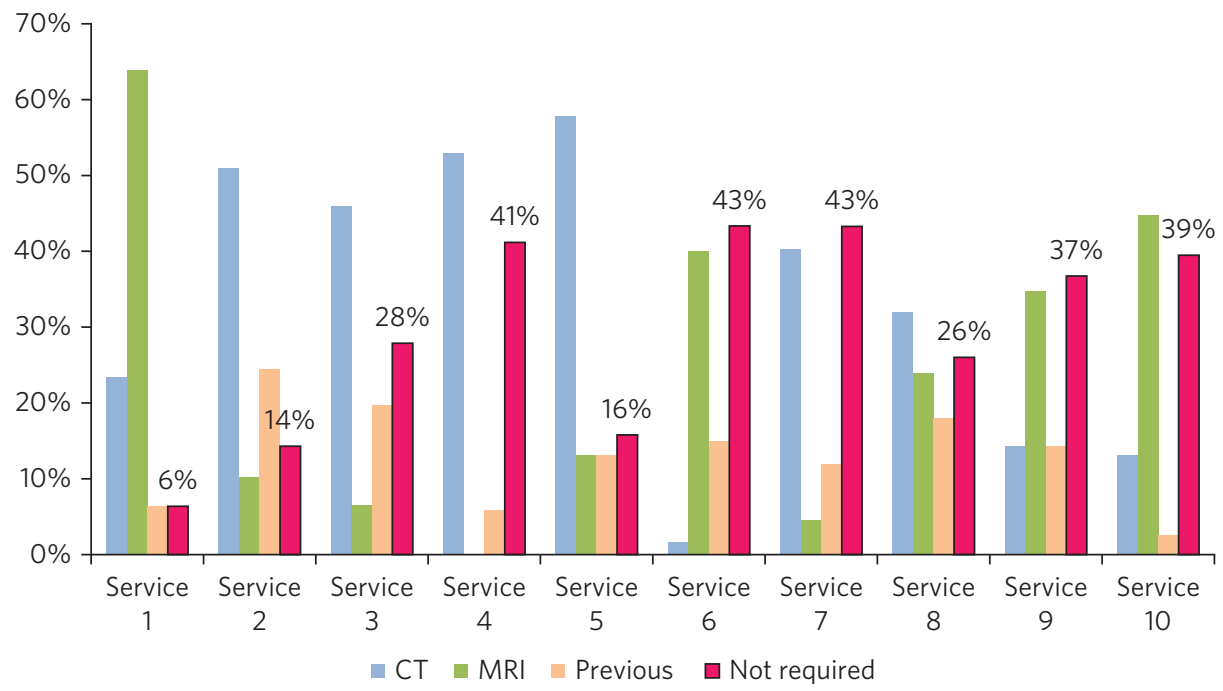

Fig. 2 Subtype diagnosis.

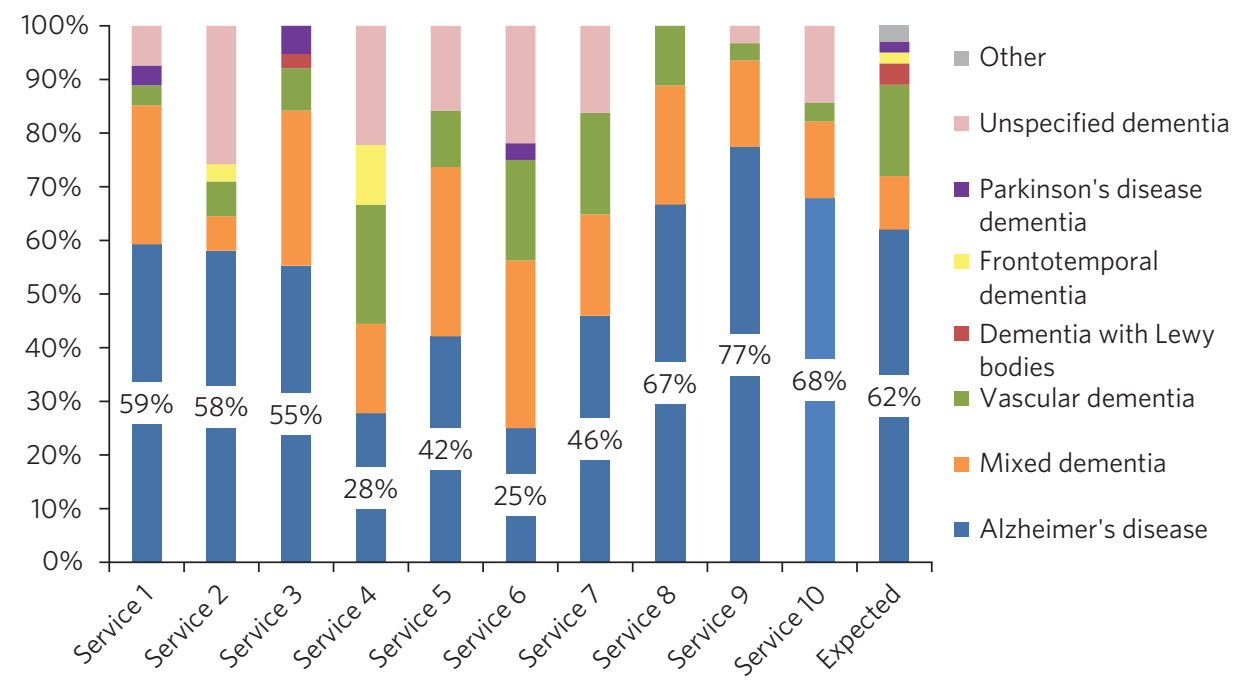

gave four options for the reason for delay in initial assessment; the most commonly selected reason was 'not known' (140 patients) followed by service capacity constraints (50) and patient choice (49). Only one assessment was delayed owing to a poor-quality referral.

Of those patients diagnosed with dementia, the average waiting time from referral to diagnosis varied between

\begin{tabular}{|lccc|}
\hline Table 1 & Variation in subtype diagnosis & \\
$\begin{array}{l}\text { Dementia } \\
\text { subtype }\end{array}$ & $\begin{array}{c}\text { Expected } \\
\text { percentage of } \\
\text { cases }\end{array}$ & $\begin{array}{c}\text { Overall } \\
\text { percentage } \\
\text { diagnosed }\end{array}$ & $\begin{array}{c}\text { Range } \\
\text { between } \\
\text { services }\end{array}$ \\
\hline $\begin{array}{l}\text { Alzheimer's } \\
\text { disease }\end{array}$ & $62 \%$ & $53 \%$ & $25 \%-77 \%$ \\
\hline $\begin{array}{l}\text { Vascular } \\
\text { dementia }\end{array}$ & $17 \%$ & $10 \%$ & $3 \%-22 \%$ \\
\hline $\begin{array}{l}\text { Mixed } \\
\text { dementia }\end{array}$ & $10 \%$ & $21 \%$ & $6 \%-32 \%$ \\
\hline
\end{tabular}

services from 5 to 23 weeks. Overall, $30 \%$ of patients were diagnosed within 6 weeks of referral (varying from 0 to $79 \%$ of patients per service).

A significant proportion of patients waited more than 30 days for a brain scan. In seven services, over half of patients waited more than 30 days for an MRI scan and in six services over half of patients waited more than 30 days for a CT scan.

\section{Post-diagnostic support}

Cognitive stimulation therapy (CST) was available in seven services. Forty-five patients (16\%) declined CST, with seven of these patients reporting that the service was not accessible. Overall, $26 \%$ of patients were deemed not appropriate for CST, varying between services from $10 \%$ to $67 \%$. Overall, only one in five patients diagnosed with dementia were offered and accepted CST.

Overall, $66 \%$ of people were referred to a dementia adviser. This varied between services from $49 \%$ to $94 \%$. 
Overall, $20 \%$ of patients consented to being contacted about research (varying from 0 to $80 \%$ ) and $20 \%$ declined; there was no documented discussion about research in $50 \%$ of notes.

START (strategies for relatives) was only offered in three out of the ten services; however, the audit specifically asked only about START, not other forms of psychoeducation for carers.

Overall, the number of patients offered cholinesterase inhibitors (CEIs) was $87 \%$ of the total number of potentially appropriate patients (i.e. those diagnosed with Alzheimer's disease, mixed dementia, dementia with Lewy bodies or Parkinson's disease dementia). However, in three services the number of patients offered CEIs was less than $65 \%$ of the number of potentially appropriate patients, and in one service it was less than $50 \%$. Overall, $6 \%$ of patients declined CEIs inhibitors, varying from 0 to $19 \%$ per service.

\section{Quality improvement projects}

In response to the audit results, the London Dementia Clinical Network implemented four quality improvement projects, as follows.

(1) Streamlining memory service pathways. All 30 memory services in London were offered a meeting with J.D.I. and L.C., at which their clinical pathway was mapped using value stream mapping principles and lean methodology ${ }^{8}$ and opportunities for efficiencies were identified. 22 services accepted and were visited. A thematic summary of this programme was published in $2017^{9}$ and disseminated at a number of regional and national forums, including the MSNAP annual conference.

(2) Implementing NICE guidelines. The 2018 NICE dementia clinical guideline ${ }^{10}$ makes several recommendations relevant to the variations listed above. All 32 CCGs in London were offered a meeting with the team from the London Dementia Clinical Network to review their action plan for meeting the requirements of the new guideline. To date, nine CCGs have been visited, with further meetings planned for 2019 .

(3) Non-dementia pathways. A working group was established by the London Dementia Clinical Network to develop bespoke advice for primary care and memory services in assessing and managing patients with the following presentations: (i) mild to moderate depression and/or anxiety; (ii) cognitive concerns in the context of alcohol misuse; (iii) MCI; (iv) functional cognitive disorder. This was published in August 2018. ${ }^{11}$

(4) Neuroimaging guidance. J.D.I., L.C. and a consultant old-age psychiatrist developed a guideline to help memory service clinicians decide which patients should be scanned and which imaging modality to choose. This was published in August 2018. ${ }^{12}$

\section{Discussion}

Memory services have developed rapidly in the UK over the past ten years, largely in response to the ambitions set out in the National Dementia Strategy. ${ }^{13}$ The number of patients seen in memory clinics in England increased fourfold between 2011 and 2013, with a further $31 \%$ average increase between 2013 and $2014 .{ }^{14}$ The NICE dementia quality standards (2010) require that 'People with suspected dementia are referred to a memory assessment service specialising in the diagnosis and initial management of dementia' but do not address specific issues such as waiting times and diagnostic accuracy. ${ }^{15}$ The Memory Services National Accreditation Programme has developed a series of quality markers which are enforced through an accreditation system consisting of self-assessment and peer review. ${ }^{16}$ However, data in the academic literature on individual memory service performance are limited, ${ }^{17-20}$ and there are no data in the peer-reviewed literature comparing performance between services according to standardised criteria.

The Royal College of Psychiatrists performed national memory service audits in England in 2013 and 2014. These reported on time from referral to initial assessment and diagnosis (national averages 8.55 and 13.92 weeks, respectively, in 2014), the proportion of patients diagnosed in the early stage of dementia, and the number of patients accessing CST and post-diagnostic counselling. ${ }^{14}$ No other data on clinical outcomes for individual patients were obtained. A similar exercise was conducted in Wales in $2014 .^{21}$ By contrast, the National Audit of Dementia, which compares in-patient care for people with dementia in the acute hospital sector, is currently in its fourth cycle and requires trusts to complete a detailed case note review of a representative number of patients (with the exact number depending on the size of the hospital). ${ }^{22}$

The aim of the London memory service audit is to identify unwarranted variation in care between providers, and to mitigate this with focused quality improvement measures. We followed a Plan Do Study Act (PDSA) cycle, starting with a pilot audit, then refining the methodology and conducting a more definitive audit, the results of which we report here, followed by the implementation of a quality improvement programme. A second cycle of the audit is planned for 2019 , after the quality improvement measures have had time to diffuse across the sector.

As described above, the audit revealed variation in diagnostic pathways, waiting times, diagnosis and post-diagnostic support.

Several services are reporting very low numbers of people consuming alcohol. This may be due to underreporting by patients or a lack of standardised questioning from clinical staff. Services may need to consider using a validated alcohol screening tool, such as the Short Michigan Alcoholism Screening Test-Geriatric Version ${ }^{23}$ to support clinical practice.

The variation in neuroimaging rates is likely due to differences in clinical decision-making regarding which patients require a scan as part of their assessment. In postaudit discussions with memory services, we have ascertained that the choice of CT as opposed to MRI is determined by a combination of local availability and clinical preference. The 2018 NICE dementia guideline does not specify whether MRI or CT is preferred, except if the subtype is uncertain and vascular dementia is suspected. ${ }^{10}$ The imaging guidance document published by the London Dementia Clinical Network in 2018 will support a reduction in variation. ${ }^{12}$ It suggests that $\mathrm{CT}$ is a suitable option in most older people, but in uncertain cases of vascular dementia and atypical presentations MRI might be more appropriate. 
The variation in subtype diagnosis is unlikely to be explained by differences in patient demographics between London boroughs. This variation may indicate lack of adherence to standardised diagnostic criteria. The 2018 NICE guideline states that clinicians should use validated criteria to guide clinical judgement when diagnosing dementia. ${ }^{10}$ It may be beneficial for clinicians to audit their individual practice against these criteria. Services were not provided with a definition of mixed dementia, which may have contributed to the difference in the rate of diagnosis of this condition.

The NHS England dementia implementation guide was published in $2017^{24}$ and was followed up by the National Collaborating Centre for Mental Health's Dementia Care Pathway in 2018. ${ }^{25}$ These documents state that services should increase the number of people diagnosed and starting treatment within 6 weeks of referral to a memory service. This audit has highlighted that while there is wide variation in waiting times, some services are able to reach the 6 week pathway ambition. Memory services should consider how they can streamline pathways in order to work towards this ambition, e.g. using value stream mapping methodology ${ }^{8}$ to identify where efficiencies can be made according to lean principles. A guidance document on streamlining memory services was published in 2017, ${ }^{9}$ which highlights examples of efficient pathways from current practice.

A significant number of people (particularly those under the age of 65) attending memory services do not have dementia, which might affect waiting times. Services should consider developing specific pathways for these patients. Pathways for common non-dementia diagnoses (MCI, alcohol misuse, mild to moderate depression and anxiety, and functional cognitive impairment) were published in 2018 to support this. ${ }^{11}$

The new NICE dementia clinical guideline published in June $2018^{10}$ highlights access to CST and psychoeducation for carers and care coordinators. It is clear from the audit that a significant number of appropriate patients and carers are not being offered these services. While care coordination was not specifically asked about in the audit, variation was noted in the percentage of patients who were offered a 'dementia advisor' type service. Providers and commissioners should review current practice and service provision against the updated NICE guideline using the baseline assessment tool $^{26}$ and consider opportunities to improve access to evidence-based post-diagnostic support.

About one in four patients in our audit were deemed not appropriate for CST, and only one in five ultimately accepted it. The audit did not capture the reason for this, but services should attempt to widen the accessibility of CST in a way that reflects the cultural diversity of the eligible population.

The audit also highlighted variation in prescribing and suggested that in some services not all eligible patients are being offered CEIs. There were also a significant number of patients who declined CEIs in some services, which suggests that the information provided to patients and carers about the risks and benefits of CEIs may differ between services.

Data from Join Dementia Research (JDR) ${ }^{27}$ demonstrates that between January and December 2016 only 191 people living with dementia (excluding MCI) signed up to JDR in London, although this number does not include people not signed up to JDR but who are on local research databases. The audit found that in half of all the patients seen there was no documented discussion about research. These findings may suggest that research is not being routinely mentioned or discussions are not being documented in clinical notes.

Information on the service specification of the memory services was not collected as part of the audit. Further discussions with services has highlighted some variation in staffing numbers, and professional and grade mix, which could have contributed to the variation found in the audit.

In summary, we have developed an audit process that allows for comparison between memory services. When used in parallel by ten London memory services it has demonstrated variation between providers. We have implemented several targeted quality improvement projects to reduce this and plan to re-audit London memory services in 2019. As memory services undergo significant expansion and performance management in order to meet the National Health Service's ambitions for faster diagnosis and higher dementia diagnosis rates, the auditing of process and outcome measures should become routine. The tool reported here could serve as a template for a future national audit.

\section{About the authors}

Laura D. Cook is Programme Lead at the Dementia Clinical Network NHS England (London Region); Katie E. Nichol is Project Manager of the Dementia Clinical Network NHS England (London Region); Jeremy D. Isaacs is a Consultant Neurologist at St George's University Hospitals NHS Foundation Trust, and Effective Diagnosis Lead of the Dementia Clinical Network NHS England (London Region)

\section{Acknowledgements}

We thank Dr Daniel Harwood from the London Dementia Clinical Network, the members of the London Dementia Clinical Network effective diagnosis working group and the memory service staff who participated in the audit

\section{References}

1 Department of Health, 2015. Prime Minister's Challenge on Dementia 2020. Available from: https://www.gov.uk/government/uploads/system/ uploads/attachment_data/file/414344/pm-dementia2020.pdf (accessed 1 September 2018)

2 Department of Health and Social Care. The Government's Mandate to NHS England for 2018-19.

3 London Dementia Clinical Network, 2016. Understanding Dementia Services Across London. Available from: www.londonscn.nhs.uk/ wp-content/uploads/2016/06/dem-memory-service-audit-062016. pdf (accessed 1 September 2018).

4 Greater London Authority, 2018. GLA Population Projection. Available from: https://data.london.gov.uk/dataset/gla-population-projections-customage-tables (accessed 29 October 2018)

5 Office for National Statistics, 2017. Adult Smoking Habits in the UK. Available from: https://www.ons.gov.uk/peoplepopulationandcommunity/healthandsocialcare/healthandlifeexpectancies/bulletins/adultsmokinghabitsingreatbritain/2017/pdf (accessed 1 September 2018). 
6 Health and Social Care Information Centre, 2016. Statistics on Alcohol England, 2016. Available from: https://files.digital.nhs.uk/publicationimport/ pub20xxx/pub20999/alc-eng-2016-rep.pdf (accessed 1 September 2018).

7 Alzheimer's Society, 2014. Dementia UK Second Edition. Available from: http://eprints.Ise.ac.uk/59437/1/Dementia_UK_Second_edition_Overview.pdf (accessed 1 September 2018).

8 Lord Z, Smith L, 2017. Bringing Lead to Life. Available from: https:// www.england.nhs.uk/improvement-hub/wp-content/uploads/sites/44/ 2017/11/Bringing-Lean-to-Life.pdf (accessed 1 September 2018).

9 London Dementia Clinical Network, 2017. Streamlining Memory Service Pathways. Available from: http://www.londonscn.nhs.uk/wp-content/ uploads/2014/11/dem-pathway-072017.pdf (accessed 1 September 2018)

10 National Institute for Health and Care Excellence, 2018. Dementia: Assessment, Management and Support for People Living With Dementia and Their Carers. Baseline Assessment Tool. Available from: https:// www.nice.org.uk/guidance/ng97/resources/

baseline-assessment-tool-excel-4849202989 (accessed 1 September 2018).

11 London Dementia Clinical Network, 2018. Non-Dementia Pathways Available from: http://www.londonscn.nhs.uk/wp-content/uploads/ 2018/08/dem-nondem-aug18.pdf (accessed 1 September 2018).

12 London Dementia Clinical Network, 2018. Neuroimaging for Dementia Diagnosis; Guidance from the London Dementia Clinical Network. Available from: http://www.londonscn.nhs.uk/wp-content/uploads/ 2018/08/dem-imaging-aug18.pdf (accessed 1 September 2018).

13 Department of Health, 2009. Living Well With Dementia; A National Dementia Strategy. Available from: https://assets.publishing service. gov.uk/government/uploads/system/uploads/attachment_data/file/ 168220/dh_094051.pdf (accessed 1 September 2018).

14 Royal College of Psychiatrists, 2014. Second English National Memory Services Audit Report. Available from: https://www.rcpsych.ac.uk/pdf/ English\%20National\%20Memory\%20Clinics\%20Audit\%20Report\% 202014.pdf (accessed 1 September 2018).

15 National Institute for Health and Care Excellence, 2010. Dementia: Support in Health and Social Care Quality Standard. Available from: https://www. nice.org.uk/guidance/qs1/resources/ dementia-support-in-health-and-social-care-pdf-58291027909 (accessed 1 September 2018).

16 Royal College of Psychiatrists, 2018. Memory Service National Accreditation Programme; Standards for Memory Services. Available from: https://www. rcpsych.ac.uk/pdf/MSNAP_Standards_6_Edition_2018.pdf (accessed 1 September 2018).
17 Mahmoud A Vandana BM, Chipperfield R, Ferrera S, Rubinsztein J. Audit of memory clinic practice against CCG guidelines: West Suffolk Hospital. Psychiatr Danub 2015; 27(1): 408-10.

18 Kuruvilla T, Zheng R, Soden B, Greef S, Lyburn I. Neuroimaging in a memory assessment service: a completed audit cycle. Psychiatr Bull 2014; 38(1): 24-8.

19 O'Kelly A, Richards G, Gorospe MF. An audit of younger patient referrals to a memory clinic. Prog Neurol Psychiatry 2015; 19(2): 21-5.

20 Bowditch E, Padmanathan P, Martinez-Clavera C, Kuruvilla T. Confusion-inducing drugs in a memory assessment service: an audit. Prog Neurol Psychiatry 2018; 22(3): 15-8.

21 Public Health Wales, 2014. Wales National Audit Memory Clinic and Memory Assessment Services. Available from: https://www.rcpsych.ac uk/pdf/Wales\%20National\%20Audit\%20-\%20Memory\%20Clinics \%20Aug\%202014.pdf (accessed 1 September 2018).

22 Royal College of Psychiatrists, 2017. National Audit of Dementia Care in General Hospitals 2016-2017 Third Round of Audit Report. Available from: https://www.rcpsych.ac.uk/pdf/National_Audit_of_Dementia_online version_FINAL.pdf (accessed 1 September 2018).

23 Naegle A, 2018. Alcohol Use Screening and Assessment for Older Adults. Available from: https://consultgeri.org/try-this/general-assessment/ issue-17.pdf (accessed 1 September 2018).

24 NHS England, 2017. Implementation Guide and Resource Pack for Dementia Care. Available from: https://www.england.nhs.uk/wp-content/uploads/ 2018/01/implementation-guide-and-resource-pack-dementia-guide.pdf (accessed 1 September 2018).

25 National Collaborating Centre for Mental Health, 2018. The Dementia Care Pathway; Full Implementation Guidance. Available from: https:// www.rcpsych.ac.uk/pdf/The\%20Dementia\%20Care\%20Pathway\% 20-\%20full\%20implementation\%20guidance.pdf (accessed 1 September 2018).

26 National Institute for Health and Care Excellence, 2018. Dementia: Assessment, Management and Support for People Living With Dementia and Their Carers. Baseline Assessment Tool. Available from: https:// www.nice.org.uk/guidance/ng97/resources/ (aseline-assessment-tool-excel-4849202989 (accessed 1 September 2018).

27 Join Dementia Research, 2018. Join Dementia Research Voluntee Registration Data. Available from: http://nhs.joindementiaresearch.nihr. ac.uk/data-and-statistics/ (accessed 1 September 2018).

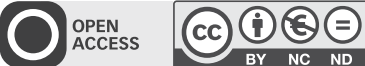

